\title{
Research on Teaching Model of Medical Information Retrieval
}

\author{
Yongrui Zhang ${ }^{1, a}$ and Jialin Gao ${ }^{1, b}$ \\ ${ }^{1}$ Department of Urology, The First Hospital of Jilin University, Jilin, China \\ azyr-912@163.com, bgjl@jlu.edu.cn
}

Keywords: Medical information retrieval; Model.

\begin{abstract}
With the advent of the Internet era, traditional teaching forms, teaching methods and teaching concepts have undergone tremendous changes, and the teaching of medical information retrieval courses has also undergone good changes. This paper will explore the new teaching model of medical information retrieval under the Internet era from the teaching modes of PICOS, MOOC, SPOC, etc., in order to change the current status of poor classroom interaction and lack of high-quality teaching resources in college medical information retrieval courses, and improve the teaching quality of medical information retrieval courses and graduate students' information literacy; and effectively change the traditional teaching evaluation system, give full play to the advantages of the network environment, and better innovate and rectify the teaching mode of medical information retrieval courses.
\end{abstract}

\section{Introduction}

The medical information retrieval course is an important course that focuses on practical teaching, aiming to cultivate students' information awareness, enable students to master information retrieval skills and improve their ability to acquire, analyze, evaluate and utilize information resources [1]. However, the course content is boring and students' learning interest is not high. In today's era of rapid development of information technology, multimedia and network have become indispensable tools in people's lives and have gradually entered the campus. The network environment not only changes students' learning environment, but also changes the traditional teaching forms, teaching methods and teaching concepts. It also changes the teaching form of the medical information retrieval course. Under the network environment, it can effectively deepen the connotation of the curriculum, and it can also incorporate a variety of modern teaching forms and concepts into teaching. It can effectively improve students' information literacy and innovation ability, and lay a solid and favorable foundation for the future development of students.

\section{The application of PICOS in medical information retrieval teaching}

Evidence-based medicine is a new medical model born in the 90s of the last century. It requires careful, accurate and wise use of the best evidence currently available, while considering the expertise and clinical experience of clinicians and considering the rights, values and expectations of patients. The three aspects will be perfectly combined to determine the patient's treatment measures [2]. The PICOS model is a clinical problem analysis model for evidence-based medicine. It converts various clinical problems into five elements of PICOS for analysis: P (population/patients/ participants) refers to the research subject's type, characteristics, type of disease suffered, etc. I (intervention) refers to the intervention or exposure factors. C (comparison) refers to a control measure or another intervention measure that can be used for comparison or an alternative that is the best. O (outcome) refers to the outcome indicator, such as the desired treatment goal. S (study design) refers to the study design scheme (eg. what type of question is the asked question, what is the best diagnosis or treatment plan). The PICOS model is characterized by the ability to translate various clinical issues such as treatment, diagnosis, etiology and prognosis into structured questions. The analysis results reflect the key elements of clinical practice in evidence-based medicine. The decomposed PICOS elements can be used as the key words of retrieval. The case teaching design of the medical information retrieval course based on the PICOS model of evidence-based medicine can infiltrate the idea of evidence-based medicine into all aspects of the teaching content of the information retrieval course, which is conducive to training medical 
students in analyzing problems, evaluating problems and scientifically rigorous thinking. It lays a solid foundation for medical students to correctly diagnose and treat diseases, thereby promoting the development of the medical profession. Case-based teaching based on the PICOS model has a wide applicability and can be used after the teaching of a search means or search method. It can also be used in the stage of comprehensive application when the teaching of a search tool or several search tools is completed. Compared to the PBL teaching method commonly used in medical information retrieval courses, the teaching method based on the PICOS model is used when students have already acquired relevant knowledge and skills. Applying them to clinical cases can be further consolidated and skilled. The time required is short, and students do not need to devote time and efforts before class. All activities are completed in the classroom and the teaching effect is easy to be controlled. In addition, this method can be used flexibly in the teaching process. Setting up simple cases can examine a single knowledge point and setting up complex cases can examine students' comprehensive use of various retrieval skills. At the same time, the introduction of PICOS model of evidence-based medicine into the analysis of cases can enable medical students to truly combine medical information retrieval skills with clinical practices, treat information retrieval as a skill to solve practical problems, and also obtain the ability to use PICOS model of evidence-based medicine to analyze and solves problems. It also enhances students' evidence-based medical thinking while doing retrieval and enables them to adapt to the needs of medical development.

\section{The application of MOOC in medical information retrieval teaching}

MOOC (Massive Open Online Courses) was based on the massive open online course that David Wylie taught at Utah State University in August, 2007. In 2012, the top universities in the United States successively set up online learning platforms. Two other concepts associated with MOOC are "microlecture" and "flipped classroom." Microlecture is also called micro-class. Different experts and scholars have different emphasis on the concept of "microlecture". The common points are: The teaching content is on a certain knowledge point within 10 minutes, teaching objectives are clear and videos are used as the teaching media. Flipped classroom is a kind of teaching mode and it is also a kind of teaching practice. Generally speaking, flipped classroom is divided into two parts: activities in the class and activities outside the class. The students initially complete the process of knowledge acceptance and understanding through the activities outside the class and further digest and absorb knowledge through activities in class. The microlecture has, to some extent, led to the flipped classroom achieving the transformation from "learning by teaching" to "learning before teaching". Introducing the flipped classroom teaching model in colleges' medical information retrieval courses is of great significance to the quality improvement of students' learning process and teachers' teaching process.

In the implementation of flipped classroom in medical information retrieval courses, the design of the task chain is essential to the entire classroom teaching effect. The design can be divided into the following stages: First, the stage of learning and understanding before class. Learning and understanding before class is the premise of flipped classroom. There are two elements: one is that teachers make teaching videos for the knowledge students need to master. They must pay attention to the rational design of the quantity and difficulty of the pre-learning content; then students should learn the targeted content before class. Students should watch the video before class and complete the targeted pre-learning tasks assigned by the teacher. They can also interact with classmates and teachers through the Internet. Second, the stage of knowledge application in class. First of all, determine the problem. The teacher sums up the problems in the learning process according to the course content and questions raised by the students. Secondly, students engage in personalized learning or group work learning to get individual or group results and report and exchange results in class. Thirdly, the teacher sorts out the completion of the learning and reviews common and personal problems. Finally, feedback evaluation is conducted. The evaluation is jointly completed by teachers and students. It should be noted that both the learning results and the learning process must be evaluated. Third, the stage of consolidation and improvement after class. At this stage, students are encouraged to apply the knowledge they learn in the unit and do certain comprehensive application. At the same time, the cultivation of students' creativity must also be considered. Fourth, the stage of after-effect evaluation of the teaching effect. This section includes: First, teachers' evaluation of students' learning effect. Second, student's evaluation of the flipped classroom teaching model. The purpose of the medical information retrieval course is to enable students to master modern information technology and find the information they need quickly and efficiently. Improving students' information abilities is the most basic purpose of the course. Flipped classroom can achieve "learning before teaching' in students' learning process so that students can learn again with problems, which is more conducive to the internalization of knowledge. However, the current flipped classroom based on microlectures has just started, and still needs continuous research and improvement.

\section{The application of SPOC in medical information retrieval teaching}

In 2013, Professor Armando Fox, the head of MOOC at the University of California, Berkeley in the United States, introduced the Small Private Online Course (shortened as SPOC). SPOC limits the size of students to dozens to hundreds of people, and sets the admission conditions for the learners of the course. It is a more refined course type. Fox believes that the use of SPOC in classroom teaching can enhance teachers' teaching methods, student's 
throughput, students' mastery and students' participation. SPOC can solve the crux of the lack of pedagogy of MOOC to a certain extent, and bring a completely different online education experience [3]. The medical information retrieval course is a required course for medical graduate students. Medical students at this stage have a strong need to study the course. However, due to the poor interaction in the classroom and lack of high-quality teaching resources, this course cannot reflect the function of medical information retrieval courses in the cultivation of graduate students' innovative ability. The teaching model of medical information retrieval courses based on SPOC has broken the traditional teaching mode. It introduces high quality teaching videos of information retrieval courses on the MOOC platform, implements a combination of classroom learning + online learning + seminar learning, focuses on information management and information utilization and values the improvement of students' knowledge discovery and innovation capabilities. According to the requirements of the syllabus of the medical information retrieval course, teachers allocate teaching contents according to the teaching plan and prepare teaching resources. Classroom learning is mainly based on fixed classes. Teachers use multimedia courseware and teach in a predominant manner. The main teaching content is the basic knowledge of information retrieval and the learning of Chinese medical database. Teachers should make PPT courseware corresponding to the content before teaching to lay the foundation for students' later online learning by themselves. Different from previous teaching methods, teachers need to prepare high quality MOOC resources of information retrieval courses from some elite universities for students' online learning. In the online learning stage, students' feedback questions should be timely collected and the results of the tests should be timely viewed. Students' learning key and difficult points should be known by the teacher and explained using the PPT courseware in the stage of seminar learning and reporting stage, and some cases should be prepared for students to do a demonstration retrieval.

The teaching model of medical information retrieval courses based on SPOC subverts traditional teaching concepts. Using high quality resources of MOOC, adopting flipped classroom model and conducting seminar-based teaching make classroom teaching more efficient which helps improve graduate students' learning interest, stimulate their scientific research enthusiasm and cultivate their innovative thinking [4]. But the SPOC model requires teachers to have a strong work enthusiasm and requires students to have a strong self-control ability in order to successfully complete the teaching plan. The SPOC teaching model enhances graduate students' learning initiative and increases their opportunities to interact with teachers which enables students' learning problems to be solved timely. The open seminar type classroom, with the participation of professional tutors, makes it clearer for students to select scientific research topics, and makes it more accurate for them to do the retrieval of literature information; the students understand their own topics more deeply through the discussion, and are more familiar with how to use the various functions of the database flexibly; the writing of internship reports improves graduate students' efficiency and ability of information utilization laying the foundation for the writing of their opening reports and theses. The SPOC teaching mode has reduced teachers' many repetitive tasks, continuously increased the content of creative work in teaching, and made teachers become the innovators of curriculum teaching models [5]. At the same time, teachers can use platform data to analyze teaching problems using a variety of methods to better improve the quality of classroom teaching. Although MOOC resources provide students with good learning resources, sometimes due to geographical and language barriers, teachers may have inconsistent teaching languages in the classroom and students may not understand the information. This requires students to listen to and practice more and get familiar with and master commonly used technical terms. In addition, students' practical operations after class take up completely the spare time. And it is necessary to repeatedly modify the retrieval strategy to do processing and analysis of literature information which undoubtedly increase students' learning burden. In the entire teaching design, teachers are not only the creators and lecturers of the multimedia courseware, but also serve as mentors, collaborators, curriculum designers and developers, researchers, learners, etc. Therefore, the SPOC teaching model requires the enthusiastic input of teachers and students to successfully complete the teaching plan.

\section{Summary}

The purpose of medical information retrieval courses is to enable students to master modern information technology and find the information they need quickly and efficiently. Improving students' information abilities is the most basic purpose of the course. The various teaching models talked about in this paper are the new teaching models of medical information retrieval in the Internet era. It is intended to give play to the advantages of the Internet environment and improve the teaching quality of medical information retrieval courses and graduate students' information literacy.

\section{References}

1. Guo Xiangfei, Li Shumin, Huang Xiaoli. Analysis on Literature Retrieval Course Teaching Method Research in China [J]. Journal of Medical Informatics, 2012, 33(12): 85-88

2. Sackett DL, Richardson WS, Rosenberg W, et al. Evidence - Based Medicine: How to Practice and Teach EBM [M]. 2nd ed. London: Churchill Livingstone, 2000

3. Luo Jiutong, Sun Meng, Gu Xiaoqing. The Innovation Research of MOOC from the Perspective of Blended Learning: Case Study of SPOC [J]. Modern Educational Technology, 2014(7):18-25 
4. Li Yan, Chen Wen, Liu Jingcheng. Exploration and Practice on the Teaching Reform of Literature Retrieval Course for Postgraduate under the Influence of the Anti-MOOC and the Flipped Classroom [J]. Journal of Academic Libraries, 2015(4):97-102
5. Guo Qianling, Zhang Huiqing, Yi Lei. Mixed Teaching Model of Literature Retrie val Course for Postgraduates Supported by MOOC [J]. Journal of Library Science, 2015(10): 82-85 